\title{
LOW COST SURVEYING USING AN UNMANNED AERIAL VEHICLE
}

\author{
M. Pérez ${ }^{\text {a }}$ *, F. Agüera ${ }^{\text {a }}$, F. Carvajal ${ }^{\text {a }}$ \\ ${ }^{a}$ EPS, Dept. of Engineering, University of Almeria, Crta. Sacramento sn, 04120 Almeria, Spain \\ Agrofood Campus of International Excellence (ceiA3) - mps515@ual.es
}

Commission I, ICWG I/5

KEY WORDS: UAV Photogrammetry, unmanned aerial vehicle, digital non metric camera, low cost equipment, surveying, orthophoto, digital elevation model

\begin{abstract}
:
Traditional manned airborne surveys are usually expensive and the resolution of the acquired images is often limited. The main advantage of Unmanned Aerial Vehicle (UAV) system acting as a photogrammetric sensor platform over more traditional manned airborne system is the high flexibility that allows image acquisition from unconventional viewpoints, the low cost in comparison with classical aerial photogrammetry and the high resolution images obtained. Nowadays there is a necessity for surveying small areas and in these cases, it is not economical the use of normal large format aerial or metric cameras to acquire aerial photos, therefore, the use of UAV platforms can be very suitable. Also the large availability of digital cameras has strongly enhanced the capabilities of UAVs. The use of digital non metric cameras together with the UAV could be used for multiple applications such as aerial surveys, GIS, wildfire mapping, stability of landslides, crop monitoring, etc. The aim of this work was to develop a low cost and accurate methodology in the production of orthophotos and Digital Elevation Models (DEM). The study was conducted in the province of Almeria, south of Spain. The photogrammetric flight had an altitude of $50 \mathrm{~m}$ over ground, covering an area of $5.000 \mathrm{~m}^{2}$ approximately. The UAV used in this work was the md4-200, which is an electronic battery powered quadrocopter UAV developed by Microdrones GmbH, Germany. It had on-board a Pextax Optio A40 digital non metric camera with 12 Megapixels. It features a $3 \mathrm{x}$ optical zoom lens with a focal range covering angles of view equivalent to those of $37-111 \mathrm{~mm}$ lens in $35 \mathrm{~mm}$ format. The quadrocopter can be programmed to follow a route defined by several waypoints and actions and it has the ability for vertical take off and landing. Proper flight geometry during image acquisition is essential in order to minimize the number of photographs, avoid areas without a good coverage and make the overlaps homogeneous. The flight planning was done using the MdCockpit software, with the module waypoint editor. Flight route file was downloaded into the quadrocopter autonomous chip via cable. A total of twelve vertical images with a longitudinal and transversal overlapping of $60 \%$ and $50 \%$ respectively were taken. The digital camera was previously geometrically calibrated. Field control points covering the whole studied area were defined over the area of interest and their coordinates were measured by a GPS. Natural targets were used as field control points. The close range photogrammetric software Photomodeler Scanner v.7 was used in this work to calibrate the camera and to carry out the photogrammetric process. The software Golden Surfer was used to produce the DEM. The planimetric and the altimetric root mean square error (RMSE) were calculated in order to check the accuracy of the products. The RMSEx was $6 \mathrm{~cm}$, the RMSEy was $4 \mathrm{~cm}$ and the RMSEy was $7 \mathrm{~cm}$. Our preliminary results demonstrate the feasibility and accuracy of orthophotos and DEMs obtained from images captured from a quadrocopter using low cost photogrammetric software. A future work can be the comparison of the products obtained following the route used in this study where the images are taken vertically with the products obtained with an orbital route where the number of images will be diminished and the photos will be taken oblique.
\end{abstract}

\section{INTRODUCTION}

The interest of producing digital terrain information datasets in an affordable price and with high precision is increasing (Bird et. al. 2010; Westoby et. al. 2012). Digital elevation model (DEM) is the usual way to describe the terrain morphology and to obtain derived information. Moreover, this information is essential for the execution of civil engineering projects which imply terrain modifications. DEM can be generated from a variety of data sources as total station surveys, laser scanning, GPS, LIDAR, SAR, etc., (Stefanik et. al. 2011), however, the cost to produce high accuracy products is generally very high. Photogrammetry from unmanned aerial vehicles (UAV) has become an alternative way to satellite and aircraft imagery (Zhang and Kovacs, 2012).

In photogrammetry it is necessary to know the internal characteristics of the camera involved in order to generate threedimensional spatial and descriptive information from two- dimensional information (Habib et. al. 2006). The recovery of these parameters is done through the camera calibration.

Camera internal parameters obtained through calibration procedures include the focal length $(f)$ of the lens, the coordinates of the centre of projection of the image $(x p, y p)$, radial lens distortion coefficients $(k 1, k 2, k 3)$ and decentring lens distortion ( $p 1, p 2)$ (Fryer, 1996). Many calibrating techniques have been developed in the last few years. A full overview of camera calibration methods and models can be found in Remondino and Fraser (2006).

The civil applications of UAVs have increased in the last few years. Some practical applications of UAVs are in the field of cultural heritage (Chiabrando et. al. 2011; Hendrickx et. al. 2011; Sauerbier and Eisenbeiß 2011), precision agriculture (Zarco-Tejada et. al. 2009; Agüera et. al. 2011; Laliberte et. al. 2011; Xiang and Tian 2011) or civil engineering (Zhang, 2008; Carvajal et. al. 2011) to cite a few.

Some recent studies have studied the morphology of the terrain through the acquisition of imagery from unmanned aerial 
systems (UAS). In 2008 Wundram and Löffler used a kite with a non-metric digital camera attached to study the mountain landscapes. Smith et. al. (2009) also used a kite with a nonmetric single lens reflex camera to collect high resolution imagery for the generation of DEMs as input to the study of geomorphological processes. Turner et. al. (2012) employed a UAV and a non-metric digital camera to produce high resolution mosaics of a terrain. Some investigations have measured the accuracy in the production of DEM or orthophotos with UAV photogrammetry but there is still a lack of studies regarding to their accuracy.

The aim of this preliminary work was to develop a low cost and accurate methodology in the production of orthophotos and DEM.

\section{MATERIALS AND METHODS}

\subsection{UAV system}

The UAV used for this study was a quadrocopter manufactured by Microdrones $\mathrm{GmbH}$ and more concretely the model md4-200 (figure 1). It is a vertical take off and landing (VTOL) UAV that can fly by remote control or autonomously thanks to a GPS waypoint navigation system. The video and telemetry down link allows the transmission of live video images, as well as all the relevant telemetry data (www.microdrones.com). The flight time is approximately 15 minutes depending of several factors such as payload weight and wind speed. It can carry a maximum of $250 \mathrm{~g}$ of payload; therefore, the sensor attached must be light. In this study we used the compact digital camera Pentax Optio A40. This camera contains a $1 / 1.7$ " CCD sensor with 12 megapixel and pixel size of $1.9 \mu \mathrm{m}$. It features a $3 \mathrm{x}$ optical zoom lens with a focal range covering angles of view equivalent to those of $37-111 \mathrm{~mm}$ lens in $35 \mathrm{~mm}$ format. The quadrocopter used in this study is considered as low cost equipment in comparison with the cost of other alternative aerial vehicles, e.g. planes or satellite.. Regarding the commercial photogrametric software used in this work, its cost is much lower than the cost of the specific digital photogrammetric software and finishing with the economical aspect of the equipment used, it is noteworthy the low price of the non-metric compact digital camera used in this work in comparison with most photogrammetric cameras.

The cost of the processing is in the same magnitude order or even less than the cost of other photogrammetric projects in which the number of images and the memory volume occupied by the files are higher. Obviously the labor needed with UAVphotogrammetry is significantly less than with land survey topographic works.

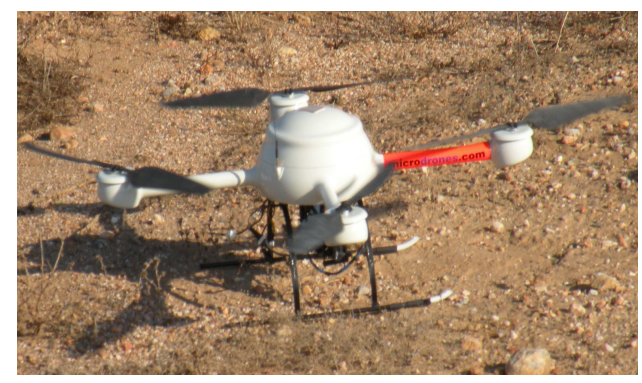

Figure 1. The vertical take off and landing UAV used for the flight mission

\subsection{Camera calibration}

The close range photogrammetric software Photomodeler Scanner v.7 was used to carry out the camera calibration using the bundle adjustment method. This software provides a calibration pattern that muss be photographed at different positions, including landscape and portrait position. The focal length was fixed at the widest angle with the focus attached to infinite. More details about the camera calibration process are described in Pérez et. al. (2011).

\subsection{Tested area and flight mission}

The tested area is a flat terrain with approximate $5.000 \mathrm{~m}^{2}$. As control points, natural features were selected across the tested area. From the total of points selected, 40 of them were used as check point (CP) and three as ground control point (GCP). The coordinates of the points were measured using a Trimble R6 GPS receiver applying a post-process with the time data corrections saved on the Almeria station, belonging to Positioning Andalusian Network, $12 \mathrm{~km}$ far away from the tested area.

The flight mission was planned taking into account a flight high over ground of $50 \mathrm{~m}$, a longitudinal and transversal overlapping of $60 \%$ and $50 \%$ respectively and the camera parameters. The tool to implement the flight planning to the quadrocopter UAV was the software MdCockpit with the waypoint editor module which is a graphical interface based on Google Earth information. The actions to do in each waypoint (camera perspective centre) were defined, including hold position, image orientation and trigger activation (see figure 2). The route had a total of twelve waypoints and three parallel lines. The route file was exported to a memory card embedded in the UAV via cable.

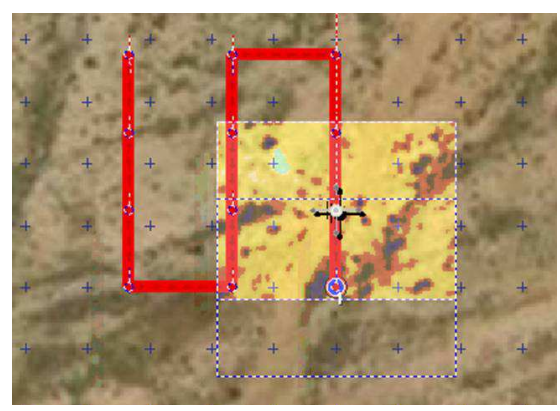

Figure 2. Flight planning with a parallel lines route and a total of twelve waypoints

\subsection{Photogrammetric workflow}

Once the flight mission was finished, the photographs from the camera were downloaded into the computer. Photomodeler Scanner software was also used for the photogrammetric process. It is a low-cost multi-application software which can be used with both, convergent and parallel photogrammetric projects (Eisenbeis, 2009). The first step in the workflow was the upload of the images followed by the introduction of the internal parameters of the camera obtained through the previous calibration. Then, through the automatic identification of the homologous points of the photographs, the relative orientation process (Wolf, 1983) was carried out. This process was realized using an image correlation algorithm as the proposed by Ackermann (1984). The time to finish this process did not exceed 10 minutes. The absolute orientation process (Wolf, 
1983) was applied by the affine transformation approach which implies translation, rotation and scale changing. For that purpose the coordinates of the three GCPs chosen in this work were selected and the photogrammetric block was fit to the UTM coordinate system, northern hemisphere and zone number 30, with the European Datum 1950. After the absolute orientation of the project, the production of 3D point clouds can be executed over the whole project. This is an automatic process where homologous pixels between images are matched through image correlation algorithms. After the point cloud generation, a manual editing process must be done to delete any significant outlier. This step could be the most time consuming of the total photogrammetric process. If the overlapping between images is high enough and the photos have a good resolution, the editing process could be greatly minimized. To transform these dense point clouds into a surface, first of all, the point clouds are merged followed by the triangulation of the model. At this stage, three products can be exported: a model, an orthophoto and a 3D viewer animation. In this work, two products were exported: the model and the othophoto. From the points exported with the model, a DEM was obtained with the Golden Surfer software.

\subsection{Accuracy assessment}

Finally, the accuracy assessment of the photogrammetric products was calculated using the root mean square error (RMSE) estimator. It is considered by some authors ( $\mathrm{Li}, 1988$; Yang and Hodler, 2000) as the most widely used global accuracy measure to evaluate the accuracy of DEMs. It was quantified by comparison of the coordinates of all CPs measured in the products of the photogrammetric projects with their real coordinates in the measured terrain with the GPS. The planimetric RMSE (RMSEx and RMSEy) of the CPs was calculated digitalizing the CPs over the orthoimages and their exportation of the coordinates. Nevertheless, the altimetric RMSE was obtained comparing the interpolated DEM height with the real height acquired by the GPS measurements.

\section{RESULTS AND DISCUSSION}

Prior to the beginning of the photogrammetric process, the internal camera parameters were defined through the camera calibration. These parameters can be seen in table 1 . Once the parameters of the camera were introduced, the relative orientation of the photographs was carried out, producing a total of 4179 automatic points. As result of the relative orientation, the position and angle of the camera with respect to the object when the photographs were taken was determined. In figure 3 the automatic points created in the process and the position of the cameras when the photos were taken is shown. This figure also displays the good performance of the flight planning.

\begin{tabular}{|lll|}
\hline & \multicolumn{2}{c|}{$\begin{array}{c}\text { Pentax Optio } \\
\text { A40 }\end{array}$} \\
\hline Focal length (mm) & 8.193 \\
\hline Format size $(\mathbf{m m})$ & $7.485 \times 5.613$ \\
\hline Principal point $(\mathbf{m m})$ & $3.723 \times 2.668$ \\
\hline $\begin{array}{l}\text { Radial distortion } \\
\text { parameters }\end{array}$ & K1 & $2.877 \mathrm{e}-003$ \\
\cline { 2 - 3 } $\begin{array}{l}\text { Kecentring distortion } \\
\text { parameters }\end{array}$ & $\mathbf{P 1}$ & $-1.838 \mathrm{e}-005$ \\
\cline { 2 - 3 } & $\mathbf{P 2}$ & $-4.515 \mathrm{e}-005$ \\
\hline
\end{tabular}

Table 1. Internal parameters of the Pentax Optio A40 camera

The overall RMS after the relative orientation of the images was 0.67 pixels. This result can be compared with the archived by Carvajal et. al. (2011) with also an overall RMS of 0.67 pixels. According to the Photomodeler online tutorial, projects with overall RMS below 1 pixel after the block adjustment can be considered accurate.

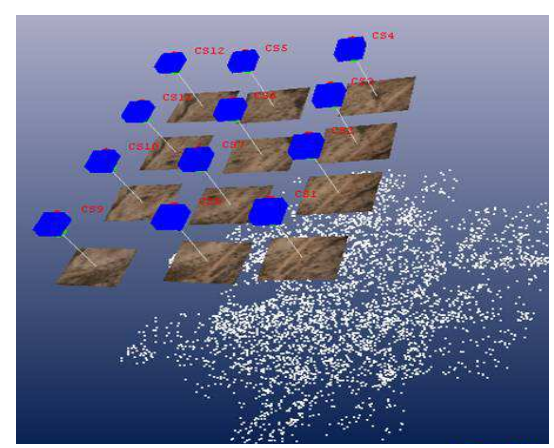

Figure 3. Mosaic of the photos and the automatic points obtained in the relative orientation

A clear advantage of the commercial software used in this study over more traditional photogrammetric software was the full automation of the relative orientation process.

After the relative orientation of the photographs and the transformation to absolute coordinates through the use of three well distributed GCP, the 3D point clouds were created. After manual edition and noise filtering, a total of 44887 points (figure 4 a) and 89336 triangles (figure 4 b) derived from these points were set up. After the triangulation of the model, the results can be also seen as shade (figure 4c) or texture mode (figure $4 \mathrm{~d}$ ). This software automatically assigns the texture in function of the perpendicular or the closeness of the triangles of the mesh, albeit the texture can be also assigned manually (Ortiz et. al. 2010).

a

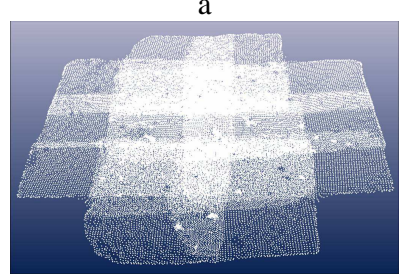

$\mathrm{c}$

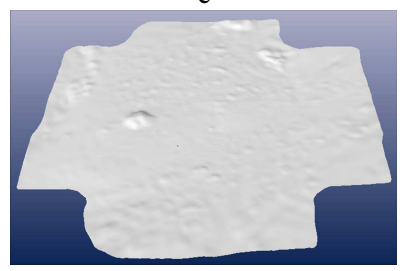

Figure 4. Details of the dense point cloud (a), triangulated points (b), shaded surface (c) and textured surfaced of the tested area (d) obtained from the photogrammetric process

Basing on the point cloud exported, a DEM was generated by the interpolation of regular grids using the radial basis function method (figure 5). The DEM was interpolated with a $10 \mathrm{~cm}$ grid. Contour lines were obtained by intersection of the DEM and a set of $0.5 \mathrm{~m}$ interval parallel planes to the horizontal plane and exported with DXF format. The small mounds that can be 
seen in the DEM are shrubs that could be found throughout the tested area.

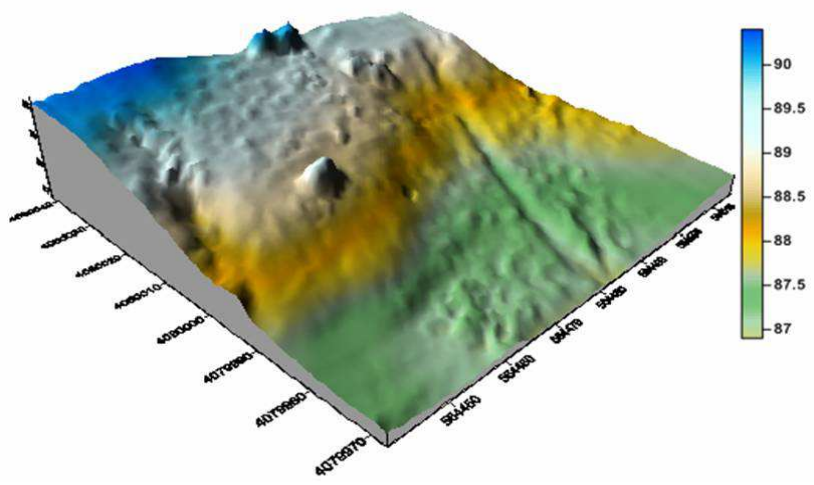

Figure 5. DEM interpolated with a $10 \mathrm{~cm}$ grid using the radial basis function method

The orthophoto was interpolated with a resolution of $1 \mathrm{~cm}$ per pixel and its image size was 11347 x 11083 pixels. In figure 6 the orthophoto of the tested area with the contour lines superimposed is shown. As can be seen in figure 6, the visually quality of the orthophoto created is very high, being able to differentiate even the smallest details.

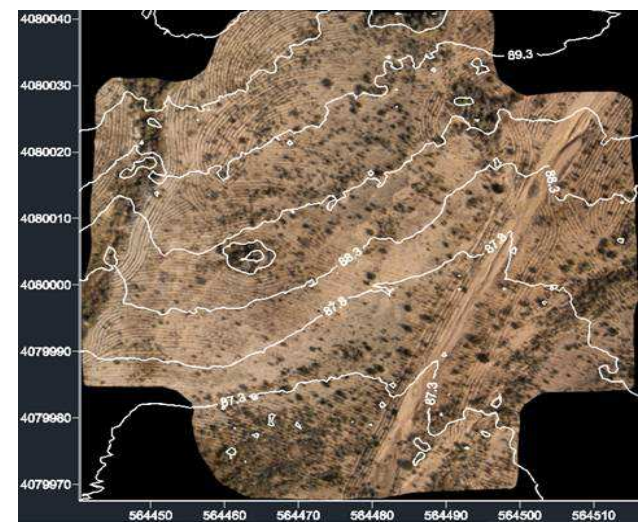

Figure $6.1 \mathrm{~cm}$ orthophoto of the photogrammetric project with contour lines with an equidistance of $0.5 \mathrm{~m}$ superimposed

The RMSEx of the tested area was $6 \mathrm{~cm}$, the RMSEy was $4 \mathrm{~cm}$ and the RMSEz was $7 \mathrm{~cm}$. This accuracy level can be considered pretty well for most of the civil engineering projects. Our results improved the obtained by Wundram and Löffler (2008) that used a kite with digital compact camera to generate DEMs of mountain landscapes. They used as error estimator the maximum error, reaching the value of $81 \mathrm{~cm}$. Our study can also be compared with the work done by Mozas-Calvache et. al. (2012). They used a kite as aerial platform and they had an altimetric difference of the DEM of $6.1 \mathrm{~cm}$. In this study has to be noted that a digital reflex camera and non low-cost photogrammetric software were used, while in our research only low-cost equipment was utilized.

\section{CONCLUSIONS}

Aerial images taken with non-metric compact cameras mounted on an UAV and using low cost photogrammetric software can be used to produce accuracy orthoimages and DEMs for most of the engineering and geomorphologic projects. The UAV Photogrammetry method employed in this work can fill in the gap between the classical aircraft photogrammetry and terrestrial surveying techniques. Moreover, the cost of the UAV imagery used in this study is fewer than the cost of satellite or manned aircraft images. The rapid availability and high resolution of the photographs makes the methodology used a feasible method to apply in order to make accuracy DEMs and orthoimages in flat terrains. A future work can be the comparison of the products obtained following the route used in this study where the images are taken vertically with the products obtained with an orbital route where the number of images will be diminished and the photos will be taken oblique. It could be also tested the use of another target points instead of natural points.

\section{REFERENCES}

\section{References from Journals:}

Ackermann F. 1984. Digital image correlation: Performance and potential application in Photogrammetry. Photogrammetric Record, 11, pp. 429-439.

Bird, S., Hogan, D., Schwab, J. 2010. Photogrammetric monitoring of small streams under a riparian forest canopy. Earth Surface Processes and Landforms, 35(8), pp. 952-970. Chiabrando, F., Nex, F., Piatti, D., Rinaudo, F. 2011. UAV and RPV systems for photogrammetric surveys in archaelogical areas: two tests in the Piedmont region (Italy). Journal of Archaeological Science, 38(3), pp. 697-710.

Habib, A., Pullivelli, A., Mitishita, E., Ghanma, M., Kim, E.M. 2006. Stability analysis of low-cost digital cameras for aerial mapping using different georeferencing techniques. The Photogrammetric Record, 21(113), pp. 29-43.

Hendrickx, M., Gheyle, W., Bonne, J., Bourgeois, J., De Wulf, A., Goossens, R. 2011. The use of stereoscopic images taken from a microdrone for the documentation of heritage - An example from the Tuekta burial mounds in the Russian Altay. Journal of Archaeological Science, 38(11), pp. 2968-2978.

Laliberte, A.S., Goforth, M.A., Steele, C.M., Rango, A. 2011. Multispectral remote sensing from unmanned aircraft: Image processing workflows and applications for rangeland environments. Remote Sensing, 3(11), pp. 2529-2551.

Li, Z. 1988. On the measure of digital terrain model accuracy. The photogrammetric record 12 (72), 873-877.

Mozas-Calvache, A.T., Pérez-García, J.L., Cardenal-Escarcena, F.J., Mata-Castro, E. Delgado-García, J. 2012. Method for photogrammetric surveying of archaeological sites with light aerial platforms. Journal of Archaeological Science, 39(2), pp. 521-530.

Ortiz, J., Gil, M.L., Martínez, S., Rego, M.T., Meijide, G. 2010. A simple methodology for recording petroglyphs using low-cost digital image correlation photogrammetry and consumer-grade digital cameras. Journal of Archaeological Science, 37(12), pp. 3158-3169. 
Sauerbier, M., Eisenbeiß , H., 2011. Investigation of UAV systems and flight modes for photogrammetric applications. The Photogrammetric Record, 26(136), pp. 400-421.

Smith, M.J., Chandler, J. Rose, J. 2009. High spatial resolution data acquisition for the geosciences: kite aerial photography. Earth Surface Processes and Landforms, 34(1), pp. 155-161.

Stefanik, K.V., Gassaway, J.C., Kochersbergerl, K., Abbott, A.L. 2011. UAV-Based Stereo Vision for Rapid Aerial Terrain Mapping. GIScience \& Remote Sensing, 48(1), pp. 24-49.

Turner, D., Lucieer, A., Watson, C. 2012. An Automated Technique for Generating Georectified Mosaics from UltraHigh Resolution Unmanned Aerial Vehicle (UAV) Imagery, Based on Structure from Motion (SfM) Point Clouds. Remote sensing, 4(5), pp. 1392-1410.

Westoby, M.J., Brasington, J., Glasser, N.F., Hambrey, M.J., Reynolds, J.M. 2012. Structure from Motion photogrammetry: A low cost, effective tool for geoscience applications. Geomorphology, 179, pp. 300-314.

Wundram, D., Löffler, J. 2008. High-resolution spatial analysis of mountain landscapes using a low-altitude remote sensing approach. International Journal of Remote Sensing, 29(4), pp. 961-974.

Xiang, H., Tian, L. 2011. Development of a low-cost agricultural remote sensing system based on an autonomous unmanned aerial vehicle (UAV). Biosystems Engineering, 108(2), pp. 174-190.

Yang, X., Hodler, T. 2000. Visual and statistical comparisons of surface modelling techniques for point-based environmental data. Cartography and Geographic Information Science 27 (2), 165-175.

Zarco-Tejada, P.J., Berni, J.A.J., Suárez, L., Sepulcre-Cantó, G., Morales, F., Millar, J.R. 2009. Imaging chlorophyll fluorescence with an airborne narrow-band multispectral camera for vegetation stress detection. Remote Sensing of Environment, 113(6), pp. 1262-1275.

Zhang, C., Kovacs, J.M. 2012. The application of small unmanned aerial systems for precision agriculture: a review. Precision agriculture, 13(6), pp. 693-712.

\section{References from Books:}

Fryer, J.G. 1996. Camera calibration. In: Close Range Photogrammetry and Machine Vision. K.B. Atkinson Ed., Whittler Publishing, Caithness, pp. 156-179.

Wolf, P.R. 1983. Elements of photogrammetry. Mc. Graw Hill.

\section{References from Other Literature:}

Agüera, F., Carvajal, F., Pérez, M. 2011. Measuring sunflower nitrogen status from an unmanned aerial vehicle-based system and an on the ground device. The International Archives of the Photogrammetry, Remote Sensing and Spatial Information Sciences, Vol. XXXVIII, Part 1/C22, PP. 33-37.

Carvajal, F., Agüera, F., Pérez, M. 2011. Surveying a landslide in a road embankment using unmanned aerial vehicle photogrammetry. The International Archives of the Photogrammetry, Remote Sensing and Spatial Information Sciences, Vol. XXXVIII, Part 1/C22, pp. 201-206.

Eisenbeiß, H., 2009. UAV Photogrammetry. Thesis Diss. ETH No 18515. Swiss Federal Institute of Technology Zurich.

Pérez, M., Agüera, F., Carvajal, F. 2011. Digital camera calibration using images taken from an unmanned aerial vehicle. The International Archives of the Photogrammetry, Remote Sensing and Spatial Information Sciences, Zurich, Switzerland, Vol. XXXVIII, Part 1/C22, pp. 167-171.

Remondino F., Fraser C. 2006. Digital camera calibration methods: considerations and comparisons. The International Archives of Photogrammetry, Remote Sensing and the Spatial Sciences, Dresden, Germany, Vol. XXXVI, Part 5, pp. 266-272.

Zhang, C. 2008. An UAV-based photogrammetric mapping system for road condition assessment. The International Archives of the Photogrammetry, Remote Sensing and Spatial Information Sciences, Vol. XXXVII, Part B5, pp. 627-632.

\section{References from websites:}

Microdrones GmbH 2013 website. http://microdrones.com/products/md4-200/md4-200-keyinformation.php. Accessed 23 March 2013.

Photomodeler software website. http://www.photomodeler.com. Accessed 15 April 2013.

\section{ACKNOWLEDGEMENTS}

This work was supported by grant P08-TEP-3870 from CICEJunta de Andalucía (Spain), co-financed with FEDER funds of the European Union. 